\title{
Are emotions exacerbating the recency bias?: An experimental study
}

\section{Felizia Arni Rudiawarni ${ }^{\star}$, I Made Narsa and Bambang Tjahjadi}

Faculty of Economics and Business, Universitas Airlangga,

Surabaya 60285, East Java, Indonesia

Email: felizia.arni.rudiawarni-2016@feb.unair.ac.id

Email: i-made-n@feb.unair.ac.id

Email: bambang.tjahjadi@feb.unair.ac.id

${ }^{*}$ Corresponding author

\begin{abstract}
This research aims to examine whether emotions can affect the recency bias in judgement and decision making (JDM). This study finds that the effect of recency bias is so strong that emotion does not affect the recency bias experienced by participants when making decisions. Further analysis shows that humans tend to weigh negative information more heavily than positive information. This research contributes to behavioural finance research in which this research incorporates an element of emotion in the recency bias, where this is so far known, is still not widely researched, especially in emerging market.
\end{abstract}

Keywords: recency bias; emotion; JDM; judgement and decision making; experimental study.

Reference to this paper should be made as follows: Rudiawarni, F.A., Made Narsa, I. and Tjahjadi, B. (2020) 'Are emotions exacerbating the recency bias?: An experimental study', Int. J. Trade and Global Markets, Vol. 13, No. 1, pp.61-70.

Biographical notes: Felizia Arni Rudiawarni is a Lecturer at Accounting Department University of Surabaya. She is interested in financial accounting, especially in earnings management. She has published papers in several international journals. Now she is pursuing her doctoral degree in accounting at Universitas Airlangga.

I Made Narsa is a Professor at Universitas Airlangga. Beside of being a Lecturer, he currently serves as the Head of the Universitas Airlangga Library. $\mathrm{He}$ is also a reviewer in various journals and conferences. His research interests are behavioural experiment and accounting management. He has published papers in national and international journals.

Bambang Tjahjadi is a Professor at Universitas Airlangga. He completed his Doctoral degree in Economics at Universitas Airlangga in 2004 . He profoundly studied about Management Accounting. He has many publications in national and international journals. He is also a consultant and facilitator in several workshops related to Strategic Management and Accounting Management. 
This paper is a revised and expanded version of a paper entitled 'Are emotions exacerbating or reducing the recency bias in decision making?: Investment case' presented at SIBR 2019 Conference on Interdisciplinary Business \& Economics Research, Tokyo, 10-11 January, 2019.

\section{Introduction}

Presentation of information sequentially may result in a primacy bias or recency bias (Hogarth and Einhorn, 1992). But among all the researches that have been done, it turns out people tend to experience the effects of recency bias (Hogarth and Einhorn, 1992; Pinsker, 2007, 2011; Daigle et al., 2015). It means that people give higher weight to the last received information compared to the previous information. As a result, people are likely to make decisions based on the latest information, without considering the information already obtained.

Recency bias affects the quality of decisions; therefore, this bias should be minimised. Various ways have been studied to minimise the recency bias on decisions, such as Trotman and Wright (1996) in the field of audit and Chalos and Poon (2000) in budgeting. Research by Sulistiawan and Wijaya (2015) suggests that the expert recommendation may decrease the recency bias if the information sequence is bad news followed by good news, but if the sequence is reversed, the use of expert recommendation is not able to decrease the recency bias. Nofsinger (2002) also examines the role of group discussions in order to decrease the effect of the recency bias against investors' decisions. From various previous studies, it appears that not all of the effort taken to mitigate the recency bias are successful.

Of the many studies on recency bias, there is still a gap in these studies, that links emotions with recency bias. When Simon (1967) proposed the theory of bounded rationality, he realised that his theory would not be complete until the role of emotion was determined. Many psychologists today assume that emotions, whether better or worse, are the dominant triggers in important life decisions (Keltner and Lerner, 2010; Scherer and Ekman, 2014). In brief, emotions and decision-making cannot be separated. Since researches on emotions and judgement and decision making (JDM) are still a new research area and recency bias is part of the decision-making process, this study seeks to fill in the gap of research in the field of emotions and recency bias. This study aims to examine whether emotions (in this study are happy and sad) will affect (exacerbate or mitigate) the recency bias in decision making.

This paper is related to international markets. Participants of this experiment are from Indonesia as the representation of market participants in emerging markets. Most of studies in recency bias are dominated by participants from developed markets, such as Pinsker (2007, 2011), Trotman and Wright (1996). Developed markets and emerging markets have different characteristics. The study of Hartono and Sulistiawan (2014) presents the evidence that stock market in emerging countries, including Indonesia are less efficient compare to those in developed market, and hence, behavioural finance theory is more able to explain the behaviour of investors. By presenting evidence from emerging markets, this study provides comparative picture from different markets (Rahman and Mustafa, 2017). 


\section{Hypothesis development}

Various studies in behavioural accounting show that the sequence in which information is received and processed affects judgement and decision making (JDM). Among these studies, evidence that JDM is influenced by recency bias is more common than that of primacy bias. Various studies have been done to minimise this recency bias. As mentioned above, Simon $(1967,1983)$ as the pioneer of bounded rationality realised that his theory would not be complete without considering the role of emotion. Research conducted by Lerner et al. (2015) organises and analyses studies related to emotions and decision making. These studies show that emotion is a powerful, widespread, predictable, sometimes dangerous and sometimes profitable decision-making factor. In various domains, important regularity arises in the mechanisms by which emotions influence judgement.

Schwarz (2000) emphasised the influence of moods and emotions experienced at the time of decision making. Many studies find that moods and emotions can influence cognitive processes (Clore et al., 1994; Schwarz and Clore, 1996). Further, according to Schwarz (2000), affective conditions affect an information-processing strategy adopted by a person. As found in many experimental studies, individuals in happy conditions tend to adopt heuristic information processing strategies, characterised by top-down processing, relying on pre-existing knowledge and low realistic attention to detail current information. Conversely, individuals who are in a sad mood, tend to adopt bottom-up processing, with little dependence on existing knowledge structures and greater attention to the current situation (Schwarz and Clore, 1996). Because it is difficult to distinguish pre-existing feelings from one's response to an existing target, individuals tend to evaluate any goal more positively when they are in a happy state rather than sad. This does not happen if individuals are aware that their feelings are irrelevant to the decisions that must be taken now (Schwarz and Clore, 1996). An individual who is in a happy mood tends to overestimate the possibility of positive outcomes and underestimate the possibility of negative outcomes and events. The opposite applies to individuals in sad conditions (Nygren et al., 1996). Luce et al. (1997) examine that decision processing in negative emotional states will become more extensive and focus more on one attribute at a time. Humans generally feel sad when things do not go as expected and feel happy if they do not face any problems. Hertel et al. (2000) show that individuals in happy conditions, tend to heuristically follow the behaviour of other players, otherwise individuals in sad conditions base their decisions on the systematic analysis of the information structure. The study proves that under different emotion, the information processing strategy is also different. Positive conditions (happy) enhance one's cooperation and vice versa for negative condition (sad).

Related with the phenomenon of recency bias, when individuals get information sequence of good news (GN) followed by bad news (BN), in general a person will be exposed to negative bias from the last information they received. Under general conditions, individuals will weigh greater for negative information. But if the individual is in a happy condition at the time he/she makes the decision, then the weight given for negative information was not as big as the individual in sad condition. By contrast, in the same order of information (GNBN), an individual in sad condition will tend to focus on one attribute at a time. In this case, the individual will tend to focus on the negative information he/she just received and further exacerbate the negative recency bias. 
$H_{1}$ : Given the sequence of good news information is followed by bad news (GNBN), undervaluation experienced by individuals in a sad condition is more severe than individuals in a happy condition.

Related with the recency bias, when the information is given in the sequence of bad news (BN) followed by good news (GN), if at the time of decision making the individual is in a happy condition, then he/she will experience a greater positive bias rather than if he/she is in a state of sadness and vice versa.

$\mathrm{H}_{2}$ : Given the sequence of bad news information is followed by good news (BNGN), overvaluation experienced by individuals in a happy condition is more severe than individual in a sad condition.

So, it can be concluded that emotions affect the decision-making process because of different cognitive processes between the two.

\section{Data and methodology}

\subsection{Participants}

This study uses undergraduate students as participants in the experiment. The undergraduate students are chosen because

- undergraduate students represent retail investors (non-professional investors)

- undergraduate students are reflection of the easiness of a person to become a customer of securities company in Indonesia

- support from previous research showing that there are no differences in recency bias between real investor and participants who act as investors (Sulistiawan and Wijaya, 2015).

Based on that arguments, this experiment uses the final year undergraduate accounting student as a participant representing a retail investor. Previous studies in emerging market also use undergraduate students as participants (Pratama, 2017).

\subsection{Experiment procedures}

This research is an experimental research with $2 \times 2$ design. The experiment is conducted in two stages:

1 Manipulation to form a happy or sad using story and movie

2 The second stage: case study.

In this study, pilots test is performed to confirm the effects of the movie used for emotional treatment (happy and sad). For the case study instrument, it was adopted from Sulistiawan and Wijaya (2015) and had been tested for validity in various studies related to the recency bias. Manipulation check has been incorporated in the instrument. Table 1 shows the division of group for this experiment. 
Table 1 Groups in this experiment

\begin{tabular}{llcc}
\hline Sequence of & & \multicolumn{2}{c}{ Emotion } \\
\cline { 3 - 4 } information & & Happy & Sad \\
\cline { 2 - 4 } & GNBN $(+++--)$ & Group 1 & Group 3 \\
& BNGN $(---+++)$ & Group 2 & Group 4 \\
\hline
\end{tabular}

At the beginning, groups with happy manipulation is separated from the group with sad manipulation. Separation is done randomly. In the beginning of experiment, the experimenters introduce themselves in each group. After the introduction, the experimenters perform the first stage, which is emotion manipulation (happy/sad). Participants in each group are asked to read the story of the movie according to the type of manipulation given with a duration of about $2 \mathrm{~min}$. The next stage participants are asked to see the movie. Movie duration is about $5 \mathrm{~min}$.

After the movie screening, the experimenters perform the second stage of the procedure by giving sequential information. The procedure of presenting sequential information are:

1 A case study was distributed for each participant. Participants work on their own.

2 In the initial information the participants are given background information of the company and asked to determine the reference point of stock price with the recommendation of the reference price is between 40 to 60 . The time is $3 \mathrm{~min}$.

3 In each sequential information, participants are asked to (a) assess the good (bad) news level by providing a 21-point scale, i.e., from -10 to +10 and (b) reassessing the company's stock price based on an initial basis. For each new information, each participant is given $2 \mathrm{~min}$ for an independent decision. If there are 6 sequential information. Total required time is $12 \mathrm{~min}$. Participants are prohibited from opening the previous page.

4 After completing six sequential information, participants are asked to fill in the questions for manipulation check. Questions are designed so that the participants are not notice that this is manipulation checklist questions).

5 The last part of the instrument is a question about participant demography.

6 After the participants finish completing the self-assignment, the instrument is submitted to the experimenters.

\section{Result and discussion}

\subsection{Data}

The number of participants in this study is 60 students. Since this is a $2 \times 2$ experiment, the participants are divided into 4 groups. After the experiment is done, we conduct a manipulation check. Based on manipulation check, 21 data cannot be used, leaving 39 data to be processed. The distribution of participants across groups are: Group $1=10$ participants, Group $2=11$ participants, Group $3=10$ participants 
and Group $4=8$ participants. So, the data is quite evenly distributed among the groups. This indicates that the differences in value arising are not caused by the distribution of unbalanced data. Descriptive statistics are presented in Table 2. From Table 2 it appears that the participants are ranging from the 5th semester until 13th semester and their average is now in 7 th semester. Thus, they are expected to have sufficient knowledge to be able to provide judgement on assessment.

Table 2 Descriptive statistics

\begin{tabular}{lccccc}
\hline & $N$ & Min. & Max. & Mean & Std. deviation \\
\hline Age & 39 & 20 & 24 & 21.49 & 1.0227 \\
Semester & 39 & 5 & 13 & 7.51 & 1.571 \\
GPA & 39 & 2.00 & 3.80 & 2.90 & 0.3652 \\
Valid N (listwise) & 39 & & & & \\
Descriptive Statistics for valuation of sequence 6 & (S6) & & & \\
Valuation of S6 Group 1 & 10 & -12 & 10 & 1.80 & 6.8280 \\
Valuation of S6 Group 2 & 11 & -8 & 15 & 2.82 & 7.7436 \\
Valuation of S6 Group 3 & 10 & -10 & 25 & 1.40 & 10.7724 \\
Valuation of S6 Group 4 & 8 & -13 & 11 & 1.38 & 7.6520 \\
\hline Total N & 39 & & & & \\
\hline
\end{tabular}

\subsection{Result}

In this study, we control participants' characteristics:

- gender

- age

- year of entry

- $\quad$ semester

- GPA.

From the regression shown in Table 3 , it is shown that characteristics of participants do not affect the decision making for valuation of stock, except for gender. Male students tend to give lower value than female students.

In this study we test the values given by participants to the sequence of the last information they received (the 6th information sequence). In Table 4, we present independent sample $t$-test between groups receiving sequential information of GNBN (+++ ---) and BNGN (--- +++). Table 4 shows that the recency effects of the information are significant across all groups. In each of the sample categories it is seen that the participants score lower on the sequence of GNBN (+++ ---) than the sequence of BNGN (--- +++) information. This indicates that participants are exposed to a recency bias. The results of this study support previous recency bias research (e.g., Pinsker, 2007, 2011). 
Table 3 Regression result for valuation

\begin{tabular}{lrc}
\hline Dependent variables & \multicolumn{1}{c}{ Coeff. } & t-value \\
\hline Constant & -9478.571 & -0.333 \\
Emotion & -6.610 & -1.099 \\
Sequential information & -20.982 & $-3.484^{* * *}$ \\
Emotion * Sequential information & 8.153 & 1.024 \\
Gender & -13.463 & $-2.470^{* *}$ \\
Age & -1.067 & -0.433 \\
Year of entry & 4.733 & 0.336 \\
Semester & 3.312 & 0.444 \\
GPA & 4.938 & 0.822 \\
\hline$F$-test & & $3.962^{* * *}$ \\
Adj. $R^{2}$ & $38.4 \%$ & \\
\hline
\end{tabular}

Dependent variable: Stock valuation; ${ }^{*}, * * * *$ are significant at $10 \%, 5 \%$ and $1 \%$, respectively.

Table 4 Independent sample t-test for information sequence across all groups

\begin{tabular}{lccc}
\hline & \multicolumn{3}{c}{ Mean $^{a}$} \\
\cline { 2 - 3 } Group & $G N B N(+++---)$ & $B N G N(---+++)$ & $t$-value \\
\hline All sample & 41.75 & 65 & $-5.506^{* * *}$ \\
Happy & 42 & 62.73 & $-3.438^{* * *}$ \\
Sad & 41.5 & 68.13 & $-4.367^{* * *}$ \\
\hline
\end{tabular}

${ }^{\mathrm{a}}$ Mean value of sequence $6(\mathrm{~S} 6) ; *, * *, * * *$ significant at level $10 \%, 5 \%$ and $1 \%$, respectively.

In Table 5, we present two-way ANOVA for the values in the 6th sequence (S6) of information in each sample category. It appears that the sequential information has a significant impact, meaning that the value given by participants in S6 is influenced by the recency bias. There is a significant difference in the mean of S6's values between participants receiving different sequence of information (GNBN and BNGN). However, the emotions and interactions between emotions and sequential information have no significant value, indicating that the value at the end of the sequence given by the participants do not differ between groups (happy and sad). This result is supported by independent sample $t$-test across groups (untabulated) which shows that the valuation between the emotional categories is not significant. The results of this study indicate that the effect of information sequence is very strong, that individual condition in the form of one's emotions (whether in happy or sad) is not able to give a significant difference when the individual gets the same information sequence.

Further analysis shows that there are interesting facts found in this study. We test participants' responses during the 4th sequence (S4), when the information begins to change direction, from good news $(\mathrm{GN})$ to bad news $(\mathrm{BN})$ and vice versa. This is shown in Table 6. 
Table 5 Valuation for S6 for each sample category (test of between-subjects)

\begin{tabular}{lcc}
\hline & Mean Square & $F$ \\
\hline Corrected model & 1801.07 & $10.04^{* * *}$ \\
Intercept & $11,0473.41$ & $615.94^{* * *}$ \\
Emotion & 57.68 & 0.32 \\
Sequence of information & 5391.17 & $30.06^{* * *}$ \\
Emotion*Sequence of information & 83.63 & 0.47 \\
Error & 179.36 & \\
\hline
\end{tabular}

$*, * *, * * *$ significant at level $10 \%, 5 \%$ and $1 \%$, respectively.

Table 6 Valuation of the fourth information sequence (S4) between happy and sad

\begin{tabular}{|c|c|c|c|}
\hline \multirow{2}{*}{$\begin{array}{l}\text { Sequence of } \\
\text { information (S4) }\end{array}$} & \multicolumn{2}{|c|}{ Mean $^{a}$} & \multirow[b]{2}{*}{ t-value } \\
\hline & Happy & Sad & \\
\hline GNBN $(+++-)$ & 50 (Group 1) & 62 (Group 3) & $-2.478 * *$ \\
\hline BNGN (---+) & 51.36(Group 2) & 54.38 (Group 4) & -0.67 \\
\hline
\end{tabular}

$*, * *, * * *$ significant at level $10 \%, 5 \%$ and $1 \%$, respectively.

Table 6 shows that in the fourth sequence (S4) when good news turns into bad news $(+++-)$, then undervaluation is more severe in Group Happy compare to Group Sad. Overreaction to bad news leads to undervaluation. But when bad news turns into good news (--- +), participants do not react symmetrically. This condition shows that participants weigh more bad news information than good news (Conrad et al., 2002). So, when people are faced to bad news after a series of good news, their punishment is more severe for companies that publish information with such a pattern (GNBN). This result implies that if the company wants to publish series of information, they should publish the negative information first and then followed by the positive one. For example: the company should disclose that this year the company's profit is decreasing because of their inefficiency in managing and handing inventories (bad news). The next sequence of information must be good news, such as: the analysts believe that the company has a growth earnings potential for the next three years because of the new alliance with the leading high-tech company (good news).

\section{Conclusion}

This study contributes to behavioural finance research, especially in investment decision making. There are some market anomalies that cannot be explained by efficient market hypothesis (Meier, 2014) and behavioural finance theory is expected to better explain these phenomena. Previous studies in the recency bias show that humans give more weight to the last information they receive. This study completes the study of recency bias, that the elements of emotion are considered in the recency bias. In this study the hypotheses are not proven. The recency bias is so strong that emotions cannot affect a person's decision that has been exposed to a recency bias. But the interesting finding in this study is it shows that individuals do not like bad news. When a person receives a 
positive set of information then the next information turns negative, the individual who is in a happy condition experiences underreaction that is more severe than the individual in sad condition. This study has implications for companies, related to how they manage their communication strategies. When companies have a mixed information, they must disclose negative information before positive information to avoid severe punishment by the market.

This research has some limitations that also become avenue for future research. First, researchers may need to use a firmer treatment to control the emotional effects. Second, this study can be improved by considering non-economic events (Gunaasih and Nursasmito, 2015) and risk disclosure (Aryani and Hussainey, 2017) as part of sequential information.

\section{References}

Aryani, D.N. and Hussainey, K. (2017) 'The determinants of risk disclosure in the Indonesian non-listed banks', Int. J. Trade and Global Markets, Vol. 10, No. 1, pp.58-66.

Chalos, P. and Poon, M.C. (2000) 'Participation and performance in capital budgeting teams', Behavioral Research in Accounting, Vol. 12, pp.199-229.

Clore, G.L., Schwarz, N. and Conway, M. (1994) 'Affective causes and consequences of social information processing', Handbook of Social Cognition, Vol. 1, pp.323-417.

Conrad, J., Cornell, B. and Landsman, W.R. (2002) 'When is bad news really bad news?', The Journal of Finance, Vol. 57, No. 6, pp.2507-2532.

Daigle, R.J., Pinsker, R.E. and Pitre, T.J. (2015) 'The impact of order effects on nonprofessional investors' belief revision when presented a long series of disclosures in an experimental market setting', Accounting Horizons, Vol. 29, No. 2, pp.313-326.

Gunaasih, S.A.P.P. and Nursasmito, I. (2015) 'The evaluation of non-economic events towards the LQ-45 index in Indonesia stock exchange by using event study method', Review of Integrative Business and Economics Research, Vol. 4, No. 2, pp.106-120.

Hartono, J. and Sulistiawan, D. (2014) 'The market quality to technical analysis performance: Intercountry analysis', Gadjah Mada International Journal of Business, Vol. 16, No. 3, pp.243-254.

Hertel, G., Neuhof, J., Theuer, T. and Kerr, N.L. (2000) 'Mood effects on cooperation in small groups: does positive mood simply lead to more cooperation?', Cognition and Emotion, Vol. 14, No.4, pp.441-472.

Hogarth, R.M. and Einhorn, H.J. (1992) 'Order effects in belief updating: the belief-adjustment model', Cognitive Psychology, Vol. 24, No.1, pp.1-55.

Keltner, D. and Lerner, J.S. (2010) 'Emotion', in Fiske, S.T., Gilbert, D.T. and Lindzey, G. (Eds.): Handbook of Social Psychology, John Wiley \& Sons, Hoboken, NJ, pp.317-352.

Lerner, J.S., Li, Y., Valdesolo, P. and Kassam, K.S. (2015) 'Emotion and decision making', Annual Review of Psychology, Vol. 66, pp.33.1-33.25.

Luce, M.F., Bettman, J.R. and Payne, J.W. (1997) 'Choice processing in emotionally difficult decisions', Journal of Experimental Psychology: Learning, Memory, and Cognition, Vol. 23, No.2, pp.384-405.

Meier, C. (2014) 'Adaptive market efficiency: review of recent empirical evidence on the persistence of stock market anomalies', Review of Integrative Business and Economics Research, Vol. 3, No. 2, pp.268-280.

Nofsinger, J.R. (2002) The Psychology of Investing. Routledge, New York, USA. 
Nygren, T.E., Isen, A.M., Taylor, P.J. and Dulin, J. (1996) 'The influence of positive affect on the decision rule in risk situations: focus on outcome (and especially avoidance of loss) rather than probability', Organizational Behavior and Human Decision Processes, Vol. 66, No.1, pp.59-72.

Pinsker, R. (2007) 'Long series of information and nonprofessional investors' belief revision', Behavioral Research in Accounting, Vol. 19, No.1, pp.197-214.

Pinsker, R. (2011) 'Primacy or recency? A study of order effects when nonprofessional investors are provided a long series of disclosures', Behavioral Research in Accounting, Vol. 23, No. 1, pp.161-183.

Pratama, A. (2017) 'Machiavelism, tax knowledge, and ethical perceptions of tax avoidance: survey of undergraduate students in West Java, Indonesia', Int. J. Trade and Global Markets, Vol. 10, No. 1, pp.83-90.

Rahman, M. and Mustafa, M. (2017) 'Financial deepening and stock market returns: panel data analyses for selected developed and developing economies', Int. J. Monetary Economics and Finance, Vol. 10, No. 1, pp.96-109.

Scherer, K.R. and Ekman, P. (Eds.) (2014) Approaches to Emotion, Psychology Press. New York, USA.

Schwarz, N. (2000), 'Emotion, cognition, and decision making', Cognition and Emotion, Vol. 14, No. 4, pp.433-440.

Schwarz, N. and Clore, G.L. (1996) 'Feelings and phenomenal experiences', Social Psychology: Handbook of Basic Principles, Vol. 2, pp.385-407.

Simon, H.A. (1967) 'Motivational and emotional controls of cognition', Psychological Review, Vol. 74, No. 1, pp.29-39.

Simon, H.A. (1983) Reason in Human Affairs, Stanford Univ. Press, Stanford, CA.

Sulistiawan, D. and Wijaya, R.E. (2015) 'The role of an expert recommendation in group discussion to minimize recency bias: an experimental study in investing decision', Int. J. Applied Business and Economic Research, Vol. 13, No. 7, pp.4933-4943.

Trotman, K.T. and Wright, A. (1996) 'Recency effects: task complexity, decision mode, and taskspecific experience', Behavioral Research in Accounting, Vol. 8, pp.175-193. 